\title{
VIOLÊNCIAS NA ESCOLA
}

\author{
Violence in schools
}

\author{
Rosa Maria de Almeida Macedo ${ }^{[a]}$, Maria do Carmo Alves Bomfim ${ }^{[b]}$ \\ [a]Mestre em educação, Professora da Universidade Federal do Piauí (UFPI), \\ vinculada ao D epartamento de Fundamentos da Educação (DEFE), Teresina, PI \\ - Brasil, e-mail: rosa.mam@ hotmail.com \\ ${ }^{[b]}$ D outora em Educação História e Filosofia da Educação, Professora da Universidade \\ Federal do Piaú (UFPI), vinculada ao Departamento de Fundamentos da Educação \\ (DEFE), Teresina, PI - Brasil, e-mail: carmicita@ig.com.br
}

\section{Resumo}

A violência tem se tornado um dos principais motivos de queixas de professores, pois, de evento esporádico, se tornou frequente na rotina da escola. Sua recorrência preocupa e o seu enfrentamento é considerado um desafio que se impõe aos pais, educadores e autoridades. Apesar disso, é um fenômeno pouco compreendido e sobre o qual pairam muitas dúvidas. Daí o interesse de realizar um estudo objetivando investigar a existência de violências no ambiente escolar; formas de manifestação e percepções de alunos e professores sobre esse fenômeno. 0 estudo foi realizado de agosto de 2006 a abril de 2007, em oito escolas públicas de três municípios do Maranhão: São Luis, Timon e Açailândia e envolveu 566 sujeitos, sendo 446 alunos do ensino fundamental e médio e 120 professores. Aplicaram-se questionários do tipo misto nos 566 sujeitos, sendo um instrumental específico para os professores e outro para os alunos e realizadas entrevistas em grupos focais com uma amostra representativa, composta de 52 alunos e 15 professores. Os dados foram

Rev. Diálogo Educ., Curitiba, v. 9, n. 28, p. 605-618, set./ dez. 2009 
analisados a partir das ideias de autores como: Abramovay e Rua (2002); Abramovay e Castro (2006); Gatti (2005); Nogueira (2004); Di Giorgi (2004); Morin, Ciurana e Motta (2003), que tratam sobre a temática. A leitura e interpretação dos dados mostraram que existem violências nas escolas investigadas e nos seus entornos; que a violência se expressa de diferentes modos, mais explicitamente por meio de agressões verbais e de incivilidades; ou sub-repticiamente, através de ameaças e de atitudes preconceituosas e que as relações interpessoais são fragilizadas.

Palavras-chave: Violências. Escola. Juventudes.

\begin{abstract}
Violence has become one of the main reasons for complaints from teachers, because of sporadic event, has become frequent in the routine of school. His worries recurrence and its confrontation is considered a challenge that is needed for parents, educators and authorities. Nevertheless, it is a poorly understood phenomenon and about which many questions hanging. Hence the interest in conducting a study aimed to investigate the existence of violence in the school environment, forms of expression and perceptions of students and teachers on this phenomenon. The study was conducted from August 2006 to April 2007, in 08 public schools in three municipalities of Maranhão: San Luis, Timon and Açailândia and involved 566 subjects, with 446 students in middle and elementary schools and 120 teachers. It was applied questionnaires of the type mixed with the 566 subjects, being an instrument specifically for teachers and other students and to conduct interviews in focus groups with a representative sample, consisting of 52 students and 15 teachers. The data were analyzed from the ideas of authors such as: Abramovay Street (2002); Abramovay and Castro (2006), Gatti (2005); Nogueira (2004); Di Giorgi (2004); Morin, Ciurana e Motta (2003), which treats about the subject. The reading and interpretation of the data showed that there is violence in schools investigated and its surroundings; that violence is expressed by different modes, more explicitly, through verbal and incivilities, or by stealth, through threats and attitudes prejudiced and that interpersonal relations are fragile.
\end{abstract}

Keywords: Violence. School. Youth.

Rev. Diálogo Educ., Curitiba, v. 9, n. 28, p. 605-618, set./ dez. 2009 


\section{INTRODUÇÃO}

A violência embora não seja exclusiva dos tempos hodiernos, coloca-se hoje como um fenômeno de caráter devastador, assumindo formas e nuances anteriormente nunca vistas. Quando o assunto é a violência, não há privilegiados, pois qualquer pessoa, independente de cor, raça ou condição social, é ou pode ser afetada por ela. No entanto, é preciso considerar que existem alguns grupos ou segmentos, que se encontram mais vulneráveis diante deste fenômeno. No Brasil, dentre os grupos mais atingidos, destacam-se, infelizmente, os grupos de jovens e os seus espaços de socialização, incluído, entre estes, o universo escolar. Com efeito, a violência não somente vitimiza os jovens na rua, na favela, na periferia ou no trânsito. Ela "persegue" os jovens aonde vão e se torna cada vez mais presente, sob diversas formas, nas escolas do país. Diante disso, o que fazer?

Sabemos que paraintervirénecessário conhecer, principalmente porque a violência, enquanto um conceito relativo possui características multifacetadas e próprias de cada contexto em que se manifesta. No sentido, pois, de conhecer a realidade para nela realizar intervenções eficazes foi realizada a pesquisa Violências na Escola, ${ }^{1}$ com 0 objetivo de detectar a existência e as formas de violências mais comuns no ambiente escolar, buscando investigar quais as percepções que alunos e professores têm sobre esse fenômeno. A pesquisa aborda as violências entendidas como todo tipo de dano físico ou simbólico que se impõe a indivíduos ou grupos e que esteja associado a fatores como pobreza, desigualdade social, falha de comunicação, dentre outros. Referem-se também à perda de legitimidade (como uso da razão, consentimento e diálogo) e às formas de relações onde o poder é exercido pelas armas, a força física, o medo, a intimidação, o não-respeito pelo outro.

Nesse texto, estão apresentados os resultados do estudo e, a partir deles, algumas considerações que não se colocam como conclusões, mas como reflexões acercado fenômeno daviolêncianos contextos pesquisados.

\section{A escola: lugar de juventudes ou lugar de violências?}

No Brasil, a condição juvenil é vivida de forma desigual e diversa. O s jovens representam hoje uma grande parcela da população e se revelam, de fato, como sendo "muitas juventudes" caracterizadas

1 A pesquisa foi realizada através da parceria O bservatório de Juventudes e Violências na Escola - Núcleo UFPI e Centro da Juventude para a Paz, entidade ligada aos Missionários Combonianos Nordeste.

Rev. Diálogo Educ., Curitiba, v. 9, n. 28, p. 605-618, set./ dez. 2009 
por classe social, cor, gênero e local de moradia. Também, representam um dos segmentos populacionais mais fortemente atingidos pelos mecanismos de exclusão social, sendo apontados pelas estatísticas como os grupos mais vulneráveis. Essas juventudes vivem aparentemente sem perspectivas, são marcadas por uma extrema diversidade e expressam as diferenças e as desigualdades sociais que caracterizam nossa sociedade. A o mesmo tempo, representam um contingente populacional bastante significativo em idade produtiva, que constitui uma importante força a ser mobilizada no processo de desenvolvimento de nosso país.

É muito comum associar os jovens a situações de violência. Sem dúvida, o fenômeno da violência está visivelmente presente em nossa sociedade, em nossas vidas, em nosso cotidiano. Aliás, aqui também se pode falar de "violências" quando a ação violenta é entendida como quaisquer danos a pessoas em graus variáveis, seja em sua integridade física, seja em sua integridade moral. Nesse contexto de violências, as juventudes são pensadas ora como agentes de violência, ora como vítimas. Sem dúvida, os jovens se envolvem em situações de violências, sendo vítimas e autores. Porém, não é possível, a partir disso, estabelecer-se uma relação de causalidade, de determinação. Ser jovem não significa ser violento, pois as violências não se expressam somente entre os jovens.

A violência é um fenômeno que atinge a todas as classes sociais, a todos os gêneros e gerações. Ultrapassafronteiras geográficas, perpassa diferenças étnicas, políticas, portanto, é enganoso pensar que se trata de um fenômeno exclusivo de alguma localidade ou espaço social, de algum segmento ou classe social.

Por isso mesmo, talvez poucos temas têm merecido tanto a atenção, dos estudiosos e especialistas, como o da violência. No entanto, trata-se de um fenômeno de difícil de conceituação. D e acordo com Abramovay e Castro (2006) a pluralidade de abordagens contribui para que não exista um consenso em relação ao que se define como violência. A pesar disso, existe uma tendência na literatura de conceituála de uma forma mais ampla, entendendo-a como todas as práticas que afetam fundamentalmente os direitos humanos e de cidadania. Referemse ao respeito à integridade física do indivíduo; a igualdade perante a lei; à liberdade de pensamento e convicção; ao direito de não estar sujeito à vontade de outrem; aos direitos coletivos (associações, cooperativas, etc.), sociais (saúde, educação, lazer), aos direitos nas relações privadas e aos direitos às diferenças referentes às categorias de gênero, de geração, de etnia/ raça, de opção política.

Rev. Diálogo Educ., Curitiba, v. 9, n. 28, p. 605-618, set./ dez. 2009 
Às vezes, a violência nos parece um fenômeno novo, próprio da nossa época, e mais intenso do que em outras épocas. Mas, isso é em parte enganoso, pois a violência não é um fenômeno recente: ao contrário, a violência é um traço de ações e interações que se perfilam no processo que é parte da história humana. Segundo Abramovay e Castro (2006), talvez o mundo nos pareça mais violento, por existir, hoje, uma sensibilidade maior em relação a certos atos antes ignorados e que passaram a ser qualificados como atos de violência. Por outro lado, alguns atos ou atitudes, antes considerados como violentos foram banalizados, adquirindo uma aparência de naturalização. Q uantas práticas sociais são manifestadas, sem que desperte mais em nós a indignação ou, sequer o espanto! Para as autoras, a banalização da violência que se expressa na indiferença, é provocada pela saturação de informações e notícias; na desconsideração de alguns fatos como violentos, devido à hierarquização de certas violências, consideradas como mais graves, em relação a outras, consideradas menos graves.

Podemos considerar que a violência não se apresenta de umaúnica forma, pois não se trata de um fenômeno universal, natural e estático. Ela é ressignificada, segundo tempos, lugares, relações e percepções. É importante, pois, olhar cenários, contextos, situações e processos sociais.

No contexto escolar, considera-se que existe tanto a violência na escola como violência da escola. A primeira se refere às violências produzidas fora da escola e que atravessam seus muros, chegando ao seu recinto. A segunda se refere às práticas efetivadas pelos próprios atores escolares (agressões morais, psicológica e física, discriminação racial e de gênero, política, estereótipos, institucionalização de avaliações predominantemente ou apenas quantitativas e com estímulo à mera competição; depredações do prédio e equipamentos escolares).

Nesta perspectiva, a escola é percebida como um espaço onde se reflete as violências presentes na sociedade e no seu entorno e, ao mesmo tempo, também favorece 0 aparecimento de violências. Considera-se que existem diferentes modalidades de violências das e nas escolas, que devem levar em consideração a violência urbana, mas que devem também dirigir o seu olhar à lógica de funcionamento da instituição escolar. Por isso, de acordo com Abramovay e Castro (2006) deve-se aceitar uma visão extensa da violência escolar, que incorpore a violência física, ou violência dura; a violência simbólica ou institucional e as microviolências: caracterizadas por atos de incivilidade, humilhações, falta de respeito. Estes fenômenos, segundo as autoras, combinam-se e reforçam-se mutuamente.

Rev. Diálogo Educ., Curitiba, v. 9, n. 28, p. 605-618, set./ dez. 2009 
A violêncianaescolanão éum fenômeno recentee se transformou em foco de atenção de pesquisadores e especialistas do mundo inteiro, seja pelas mudanças enfrentadas pela instituição escolar, seja pelos novos significados assumidos pela violência no mundo contemporâneo.

0 certo é que as violências em todo o mundo têm crescido de forma contínua e variada, constituindo-se num fenômeno presente no cotidiano dos vários espaços sociais de grandes centros urbanos, no caso brasileiro, revelando-se mais acentuado nas capitais dos estados. Suscitam, portanto, desafios a todos os indivíduos, a toda a sociedade civil e aos governantes para construírem novas formas para pensar e enfrentar esse fenômeno e praticarem políticas públicas, suficientes e eficazes, visando a sua redução.

\section{A metodologia da pesquisa}

O estudo foi realizado em oito escolas públicas do estado do maranhão que oferecem ensino fundamental e médio: quatro em Timon, duas em São Luís e duas em Açailândia, todas situadas na periferia. A realização da pesquisa em três contextos diferentes não teve como objetivo fazer comparações, mas fazer umaleitura dessas realidades a partir de dados concretos que possam subsidiar a definição de ações para serem implantadas e/ ou implementadas nesses contextos, onde já existe uma atuação dos missionários combonianos/ nordeste.

0 universo da pesquisa era constituído de 4.650 alunos e 247 professores das oito escolas, do qual foi selecionada uma amostra de 446 alunos (214 do sexo feminino e 210 masculino) e 120 professores ( 65 do sexo feminino e 43 masculino). ${ }^{2}$ Em Timon, a amostra selecionada foi de 196 alunos, e 56 professores; em São Luís, 103 alunos e 10 professores e, em Açailândia de 147 alunos e 54 professores. Q uanto à idade dos alunos, 359 (80,49\%), têm entre 10 a 20 anos de idade e 69 (15,47\%) acima de 20 anos, pois, a pesquisa também abordou alunos da modalidade de Educação de Jovens e Adultos - EJA. Quanto aos professores, 33 têm entre 20 a 30 anos de idade e 66 têm acima de 30 anos de idade.

A maioria dos alunos (155) vive com pai e mãe, sendo também representativo o número de alunos que moram somente com suas mães $(26,82 \%)$ e poucos os que vivem com parentes ou outras pessoas. Além

$\overline{2}$ A quantidade nem sempre fecha em $100 \%$ porque alguns sujeitos não informaram todas as respostas.

Rev. Diálogo Educ., Curitiba, v. 9, n. 28, p. 605-618, set./ dez. 2009 
disso, 269 alunos (78,42\%) moram em casa própria e apenas 56 moram em casa alugada ou emprestada. 343 alunos $(23,61 \%)$ afirmaram que há o uso de álcool ou outras drogas por parte de familiares.

A coleta dos dados aconteceu em dois momentos: no primeiro, utilizamos questionários do tipo misto (questões abertas e fechadas), compostos de 40 questões para alunos e de 37 para professores, envolvendo os seguintes temas: entorno físico, segurança, infra-estrutura, questões raciais, gênero e sexualidade, agressão física e verbal, recursos didáticos, qualidade do ensino, participação e relações de poder, armas, patrimônio, procedimentos disciplinares, drogas (consumo e tráfico), envolvimento família-comunidade, relações interpessoais e alternativas de solução no combate a violência. No segundo momento, utilizamos a técnica do grupo focal (GATTI, 2005), por ser considerada bastante eficiente quando se deseja buscar respostas para os "porquês" e "como" dos comportamentos. Essa técnica foi aplicada num ambiente fora da escola com a presença de um moderador e dois relatores e as sessões gravadas em áudio. Ao todo foram realizadas dez sessões de grupos focais, tendo em média oito participantes em cada sessão.

Como procedimento de análise e interpretação dos dados, utilizamos no primeiro momento o sistema de categorização e no segundo, utilizamos a técnica de análise de conteúdo desenvolvida por Bardin (1977). As respostas relativas às questões fechadas foram quantificadas e representadas por gráficos e tabelas. As respostas às questões abertas foram agrupadas a partir das similaridades apresentadas, assim como os conteúdos dos discursos, o que nos possibilitou organizar as informações em duas partes: na primeira, as informações que nos levam a compreender, como o ambiente escolar é percebido por alunos e professores: como a escola funciona, como são percebidas as relações interpessoais, qual a apreciação que esses sujeitos fazem sobre a escola e seu entorno. Na segunda parte, as informações que nos levam a captar as impressões dos alunos e professores sobre o fenômeno da violência e quais as possibilidades de mudanças indicadas por eles.

\section{Resultados da pesquisa - o ambiente escolar}

Os dados encontrados mostram que a maioria dos alunos (70\%) não gosta do local onde a escola está situada: a rua, o bairro e a vizinhança. A existência de gangues, segundo a afirmação de $90 \%$ dos alunos e $68 \%$ dos professores, faz com que 0 entorno da escola seja

Rev. Diálogo Educ., Curitiba, v. 9, n. 28, p. 605-618, set./ dez. 2009 
considerado "perigoso". 0 trajeto de casa para a escola e vice-versa e 0 ponto de ônibus são considerados como locais onde a qualquer momento poderá acontecer uma cena de violência.

No entanto, não é somente o entorno que é percebido desta forma. As dependências da escola, de modo geral e, particularmente, a sala de aula são consideradas por alunos $(22,4 \%)$ e professores $(20,8 \%)$ como espaços onde também ocorre violência.

Entre os professores, embora a localização da escola não seja considerada boa, é a falta de sua estrutura que é apontada por muitos professores (42\%) como aquilo que menos gostam, pois, consideram insuficiente, precária e inadequada. A falta de espaço de lazer, quadra de esportes, banheiros mal localizados e precários, são alguns dos aspectos mencionados por eles. Além disso, os professores se queixam da falta de acompanhamento dos filhos/ alunos/ as pelos pais e mães, da falta de interesse e do comportamento indisciplinado de alguns alunos; enquanto estes se queixam da violência, da falta de respeito que dizem sofrer, do desempenho dos professores, do diretor, o que mostra a diferença dos olhares dos dois segmentos.

Em relação às gangues que afirmam existir, os alunos e professores, dizem tratar-se de grupos formados por jovens, que apresentam atitudes agressivas e racistas e geralmente andam armados. Segundo os estudantes, as gangues têm envolvimento com 0 tráfico e venda de drogas e alguns membros são alunos da escola, o que facilita a venda e o consumo no espaço escolar. Muitos afirmam já ter visto roupinol, meninos usando no banheiro e alguns trazem prá si mesmo...

D e acordo com os alunos e professores, as relações entre os diversos segmentos que constituem a escola são consideradas "mais ou menos". É dessa forma que os alunos (70\%) e professores (70\%) classificam o relacionamento entre aluno-aluno, aluno-professor e aluno-funcionário. D e acordo com alguns professores, as relações são consideradas "mais ou menos", porque se trata de algo muito relativo. Algumas pessoas são mais abertas e às vezes, um simples ato afasta 0 aluno. A lém disso, depende do nível de ensino, pois com os alunos do ensino fundamental há maior aproximação, o que faz com que o relacionamento seja bom; com os alunos de ensino médio é diferente, pois, são mais distantes.

O s resultados da pesquisa mostram que a maioria dos alunos $(68 \%)$ considera a escola "mais ou menos" porque não é a melhor escola, mas, também não é a pior, existe violência entre os alunos, tem vários problemas e não tem diversão. Entre os professores a apreciação foi mais

Rev. Diálogo Educ., Curitiba, v. 9, n. 28, p. 605-618, set./ dez. 2009 
positiva e, embora muitos achem "mais ou menos" (40\%), a maioria $(60 \%)$, considera a escola onde trabalham um lugar bom porque sinto-me bem aceito; temos voz e vez; pela ótima direção.

\section{Resultados da pesquisa - escola e violência: algumas percepções}

Sobre a existência de violência no espaço escolar, tanto alunos como professores disseram ter conhecimento desse fato. 88\% dos alunos afirmam que existe violência na escola, entre os alunos, mas, que muitos professores encaram o problema como algo banal, porque sentem medo dos alunos. D e acordo com esses mesmos sujeitos, os tipos de violência mais comuns são as brigas, os xingamentos, atitudes de discriminação e preconceito ligadas à raça e à questão de gênero. 0 s atos de violência ocorrem com uma frequência média, para 37,8\% dos alunos e com muita frequência para 10,5\%.

Para 80\% dos professores existe violência na escola, embora a frequência seja pouca ou média. Para eles, a violência que se manifesta dentro da escola é decorrente, principalmente, da falta de estrutura familiar. A responsabilização recai sobre a família que não tem estrutura, não educa e assim, 0 aluno já vem com a personalidade formada eémuito difícil reverter isso, dificultando para que a escola cumpra seu papel social.

Ao apontar os tipos de violência que se manifestam no espaço escolar, são poucos os alunos e professores que afirmaram ter sofrido xingamentos ou agressões físicas por causa da cor da pele. A pesar disso, alguns afirmam: ex iste discriminação sim! 0 negro, 0 moreno e 0 preto. A sociedade faz discriminação em relação às cores das pessoas e considera mais o branco. Conforme depoimento dos alunos, muitos não querem admitir e se aceitar como negros e, por isso, se autodefinem como pardos. Pardo éa or quevai dareando! D entro da escola você tem que se definir e o pardo serve para evitar problemas.

O s xingamentos por outros motivos e as agressões físicas são apontados como tipos de violência que aparecem, cotidianamente, na escola. 38\% dos alunos e 18\% dos professores já foram xingados e 8,2\% dos alunos e 3,3\% dos professores sofreram agressões físicas. O s alunos dizem que os xingamentos ocorrem, geralmente, entre eles próprios, mas, que também existem casos em que o aluno é xingado pelo professor ou por funcionário da escola. D e outro lado, os professores dizem que, em geral, são xingados pelos alunos, assim como aqueles que já sofreram agressão física.

Rev. Diálogo Educ., Curitiba, v. 9, n. 28, p. 605-618, set./ dez. 2009 
A prática de ameaças é bastante comum e geralmente ela ocorre entre os discentes, mas existe, também, a ameaça do aluno dirigida ao professor e vice-versa. O utra prática que parece comum são os roubos, considerando que $51 \%$ dos discentes e $34 \%$ dos docentes afirmaram saber da existência de tal prática. Sobre a existência de armas dentro da escola, tanto alunos (36\%) como professores (24\%) afirmaram já ter visto armas como: canivetes, facas, estiletes e até revólver, são armas que são trazidas por alunos.

\section{CONSIDERAÇÕES FINAIS}

Verificamos que nas escolas onde o estudo foi realizado a violência existe e é percebida por alunos e professores sob olhares e perspectivas diferentes, o que é perfeitamente compreensível. Assim, como em outros espaços, a escola convive com o fenômeno da violência; nas realidades investigadas éum fenômeno que ocorre com umafrequência preocupante; discentes e docentes são ao mesmo tempo vítimas eautores; a dinâmica de funcionamento da escola reflete a própria dinâmica da sociedade e tem a ver com o seu entorno; tanto alunos e professores apresentam um discurso, às vezes, confuso e contraditório e as questões relacionadas à violência são consideradas "delicadas", daí o grande número de respostas como "não sei" ou "não vi".

Diante disso, podemos afirmar que a escola, hoje, para muitas pessoas não é mais considerada um lugar de segurança e proteção. Contraditoriamente, a escola, apesar de discursos em que se afirma como um lugar de inclusão e de convivência com a diversidade, dentro dela são engendrados mecanismos de exclusão e seleção social, contribuindo para que alguns permaneçam e muitos sejam excluídos. Em geral, os que saem, são aqueles que não conseguem responder às expectativas depositadas neles pela escola, quanto à aprendizagem, ao comportamento e ao relacionamento com os integrantes da comunidade escolar.

Neste espaço, a exclusão se dá principalmente através do desempenho escolar, da repetência, do abandono e da evasão. Em muitas escolas existe uma lógica perversa em que os alunos com maiores dificuldades, ao invés de serem vistos nas suas singularidades, são conduzidos a trajetórias escolares que tendem ao fracasso escolar, concretizado através do retraimento do aluno, do abandono, da evasão e da própria violência contra o sistema escolar.

A experiência com o fracasso escolar mina a autoestima e pode trazer significativas consequências paraavidado alunos tanto na convivência

Rev. Diálogo Educ., Curitiba, v. 9, n. 28, p. 605-618, set./ dez. 2009 
escolarquanto para toda a sua vida. D eacordo com Carrano (2000), existem pontos de tensão entre o mundo escolar e o mundo juvenil. Segundo este autor, o professor tem um papel importante no processo de integração desses dois mundos. O educador precisa tentar compreender as subjetividades, os sentimentos e as potencialidades dos alunos, que antes de serem alunos, são jovens que têm uma história, gostos, desejos, sonhos, que não devem ser reprimidos pela instituição escolar.

Podemos concluir que existe uma evidente tensão entre as lógicas dos professores, da própria escola, e a dos jovens que buscam no sistema escolar, "o ser jovem". É necessário considerar os alunos de modo que estes possam consolidar sua identidade pessoal, por meio de uma imagem positiva de si mesmo, de independência, levando em conta seus interesses, suas possibilidades e aptidões. É impossível separar a vida dentro e fora da escola, na medida em que os jovens trazem para seu cotidiano escolar sua maneira de ser, sua linguagem e cultura de uma forma aberta, flexível, natural e instável, causando conflitos entre a cultura juvenil e a cultura escolar.

A aparente apatia, o desinteresse, 0 não cumprimento das regras, a revolta contra os professores e contra a escola podem ser manifestações de que alguma coisa está errada, não necessariamente só com 0 aluno, mas também com a escola. A violência pode ser outra forma de reagir às tensões e injustiças provocadas pelo sistema escolar.

É nesse ambiente que o fenômeno das violências tem que ser analisado, por meio da compreensão do cotidiano escolar, seus problemas e suas questões.

O sistema educacional está acometido por problemas como a falta de segurança, a indisciplina, os conflitos e a eclosão de diversas modalidades de violência, deteriorando o clima, as relações interpessoais, impedindo que a escola cumpra com eficiência sua função.

As violências no espaço escolar têm um grande potencial de desorganizar a escola e o processo de ensino-aprendizagem e de desestabilizar as relações entre os atores que nela convivem, inviabilizando o cumprimento de seu papel social: formar - no sentido amplo do termo - crianças, adolescentes e jovens.

$\mathrm{O}$ certo é que se pode afirmar que a escola, hoje, deixou de ser um espaço protegido e tornou-se um lugar de insegurança e medo. A relação entre escola e violências vem se alterando de maneira acentuada a cada dia. Isso é decorrente tanto das falhas do Estado referentes à oferta e garantia de direitos humanos quanto da forma dramática e apelativa às "aventuras humanas" difundidas pela mídia, utilizadas

Rev. Diálogo Educ., Curitiba, v. 9, n. 28, p. 605-618, set./ dez. 2009 
principalmente por parte dos atores do segmento juvenil que desejam parecer "heróis". Eles o fazem como estratégia de sobrevivência, numa sociedade como a nossa fragmentada e permeada por grandes conflitos, incertezas e altamente excludente. Assim, muitosindivíduos, em particular os jovens se organizam "à margem dessa sociedade, com códigos e valores distintos", muitas vezes "ameaçando o direito à vida". É o caso dos integrantes das gangues que, por "necessidade" do controle dos respectivos territórios (bairros, áreas dos bairros), como alunos ou agentes externos, usam o espaço escolar para atacarem seus adversários, também colegas, e até mesmo, docentes e funcionários.

Como explica Bourdieu apud Nogueira e Nogueira (2004), enfatizado por Abramovay e Rua (2002, p. 32), a escola está perdendo a sua legitimidade como transmissora e produtora de saberes e valores positivos e se transformando em palco de reprodução das desigualdades sociais, além de se transformar "em lócus privilegiado para a reprodução massiva da violência estrutural e seus diversos níveis: institucional, simbólica e física”. No entanto, é prudente considerar que as relações entre escola e violência não devem ser interpretadas apenas pela direção exclusiva de ações de "fora para dentro", porque ela resulta também de relações estabelecidas no interior dela própria como ação de seus agentes: professoras/es, gestoras/ es e funcionárias/ os técnicoadministrativos. Em razão de tudo isso, esse fenômeno não pode ser tratado isoladamente, mas integrado ao conjunto dos temas inerentes ao projeto político-pedagógico da escola. Enfim, "a escola pode ser vítima, mas também autora de processos violentos". (ABRAMOVAY; RUA, 2002, p. 33). Em consequência, não é mais um espaço protegido ao reproduzir as violências da sociedade em nível macro.

É preciso uma redefinição dos papéis da escola (D I GIORG I, 2004), o que implica definir: de qual escola estamos falando? Que condições básicas essa escola deve ter? A que atende as crianças, jovens, adultos e idosos das camadas populares - a escola pública. Q uando se trata de condições, uma primeira se evidencia imediatamente (e não exclusivamente), porém decisiva: a formação dos professores e das professoras alicerçada por salários justos e biblioteca atualizada. E aqui ressalta-se formação básica (mínima exigidalegalmente para o exercício do magistério) e continuada, a que se efetiva por meio da produção de conhecimentos, atualização com leituras, debates e o exercício da prática da pesquisa e da produção de textos, sendo imprescindível o vínculo escola-família-universidade, entretanto mediado pelo conhecimento sobre: Q uem são os/ as educandos/ as? Como se caracterizam os seus contextos?

Rev. Diálogo Educ., Curitiba, v. 9, n. 28, p. 605-618, set./ dez. 2009 
Quais são as suas angústias e suas necessidades? Quais são as suas fragilidades humanas e técnicas? Q uais são as suas expectativas em relação à escola? Q uais são os desejos e projetos individuais e coletivos? Não esquecendo também da necessidade de construir olhares so bre o percurso de casa para a escola e o seu entorno.

Uma segunda condição diz respeito à abertura da escola para mães, pais, lideranças da comunidade, movimentos/ grupos juvenis e de adultos com a disponibilidade de trocar experiências, despertar a responsabilidade pela educação dos escolares e receber apoios. Não há receitas para essas práticas. Porém, no Brasil, no Piauí e, particularmente, em Teresina, há exemplos de Cultura de Paz, ainda que limitados e incipientes em termos de tempo. ${ }^{3}$

Uma terceira condição é aquela sugerida por Di G iorgi (2004, p. 143) que é acreditar na capacidade dos/ as alunos/ as de ensinar. A experiência de monitoria na escola básica, claro, com orientação e acompanhamento por parte de gestores/ as e docentes.

Uma quarta (e não a última), uma gestão escolar democrática permitindo a participação livre e ativa de todos os atores escolares: discentes, docentes, servidoras/ es de apoio e técnico-administrativos.

Tudo isso só se concretizará, segundo Morin, Ciurana e Motta (2003), se houver uma compreensão de que estamos inseridos numa sociedade complexa porque globalizada e de que o ato educativo é uma das ações mais complexas da realidade humana e que, para efetivá-la, é preciso o exercício de um método como estratégia de aprendizagem.

\section{REFERÊNCIAS}

ABRAMOVAY, M.; RUA, M. G. Violências nas escolas. Brasília: Unesco, 2002. ABRAMOVAY, M.; CASTRO, M. G. Caleidoscópio das violências nas escolas. Brasília: Missão Criança, 2006.

BARD IN, L. Análise de conteúdo. Lisboa: Edições 70, 1977.

3 Experiência do Projeto Escola-Comunidade promovido pela Secretaria Estadual da Educação e Cultura - SEDUC; Projeto Escola Aberta desenvolvido em finais de semana pela Secretaria Municipal da Educação - SEMEC; Experiência promovida pela Fundação Walter Alencar. Em outros, aquelas desenvolvidas pelos O bservatórios de Juventude e Violências nas Escolas no espaço de algumas universidades, dentre elas a do Piauí, muitas delas difundidas no livro ABRAMOVAY, Mírian (O rg.). Escolas inovadoras: experiências bem-sucedidas em escolas públicas. Brasília: Unesco, Ministério da Educação, 2004.

Rev. Diálogo Educ., Curitiba, v. 9, n. 28, p. 605-618, set./ dez. 2009 
CARRANO, P. C. R. Identidades juvenis e escola. Alfabetização e cidadania. São Paulo: Rede de Apoio à Ação Alfabetizadora do Brasil, 2000. v. 10.

D I G IO RG I, C. U ma outra escola é possível: uma análise radical e da inserção social e da democracia na escola do mundo globalizado. Campinas: Mercado de Letras/ Associação de Leitura do Brasil, 2004.

GATTI, B. A. Grupo focal na pesquisa em ciências sociais e humanas. Brasília: Liber Livro, 2005.

MORIN, E.; CIURANA, E-R.; MOTTA, R. D. Educar na era planetária. São Paulo: Cortez; Brasília: Unesco, 2003.

NOG UEIRA, M. A.; NOG UEIRA, C. M. M. Bourdieu \& a educação. Belo Horizonte: Autêntica, 2004.

Recebido: 15/ 03/ 2009

Received: 03/ 15/ 2009

Aprovado: 02/ 04/ 2009

A pproved: 04/ 02/ 2009

Revisado: 17/ 09/ 2009

Reviewed: 09/ 17/ 2009

Rev. Diálogo Educ., Curitiba, v. 9, n. 28, p. 605-618, set./ dez. 2009 